\title{
Low Temperature Annealing Effect of PFO-Poss Emission Layer on the Properties of Polymer Light Emitting Diodes
}

\author{
Su Cheol Gong and Ho Jung Chang ${ }^{\dagger}$ \\ Department of Electronic Engineering, Dankook University, 29 Anseodong, Cheonan 330-714, Korea
}

(Received April 7, 2009 : Received in revised form May 4, 2009 : Accepted June 4, 2009)

\begin{abstract}
Polymer Light Emitting Diodes (PLEDs) with an ITO/PEDOT:PSS/PVK/PFO-poss/LiF/Al structure were prepared on plasma-treated ITO/glass substrates using spin-coating and thermal evaporation methods. The annealing effects of the PFO-poss film when it acts as the emission layer were investigated by using electrical and optical property measurements. The annealing conditions of the PFO-poss emission film were 100 and $200{ }^{\circ} \mathrm{C}$ for 1,2 and 3 hours, respectively. The luminance increased and the turn-on voltage decreased when the annealing temperature and treatment time increased. After examining the Luminance-Voltage (L-V) properties of the PLED, the maximum luminance was found to be $1497 \mathrm{~cd} / \mathrm{m}^{2}$ at $11 \mathrm{~V}$ for the device when it was annealed at $200^{\circ} \mathrm{C}$ for 3 hours. The peak intensity of the PLED emission spectra at approximately $525 \mathrm{~nm}$ in wavelength increased when the annealing temperature and time of the PFO-poss film increased. These results suggest that the light emission color shifted from blue to green.
\end{abstract}

Key words polymer light emitting diode (PLED), annealing, luminance, spin coating, emission spectra.

\section{Introduction}

Generally, organic light emitting diodes (OLED) can be classified with a small molecule LED and polymer LED (PLED) according to the emission materials introduced to the devices. OLEDs have attracted considerable attention for the next generation displays because they have advantages such as low power consumption, wide color gamut and good viewing angle with a self light emission as well as thin and light devices. ${ }^{1-3)}$ OLEDs are generally manufactured using large scale thermal evaporation systems, which have disadvantages for large area display. On the other hand, PLEDs can be prepared using the spin coating and inkjet printing methods, which means that they can be manufactured at low cost. ${ }^{4-7)}$ In addition, PLEDs can be applied to flexible displays using large and rollable plastic substrates. The PLED is current operational device which emit the light through the recombination of excitons injected from anode and cathode electrodes. It is desirable to prepare the PLEDs with good interfacial adhesion property and surface morphology between electrode and organic films. ${ }^{89}$ In particular, to optimize the electron and hole recombination process at the emitting layer of PLED, it is necessary to carry out the ITO (indium tin oxide)

Corresponding author

E-Mail : hjchang@dankook.ac.kr (H. J. Chang) surface treatment and adhesion improvement between inter-layer films.

PFO-poss [Poly(9,9-dioctylfluorenyl-2,7-diyl) end capped with poss] can be applied to full color displays and white light sources because it emits various energies through energy transfer from the dopant. ${ }^{10,11)}$ It is estimated that this energy transfer is caused by both dopants and the thermal treatment conditions of the emission organic films. Until now, most of the papers have been focused on the doping effects of the emitting materials and/or new device structures in order to improve the luminance and light quantum efficiency of the PLED devices.

In this work, the PLED devices with ITO/PEDOT:PSS/ PVK/PFO-poss/LiF/Al structure were prepared on the plasma-treated ITO/glass substrates. The dependence of heat treatment (annealing) effects of the PFO-poss emission film layer on the electrical and optical properties of the PLED devices were investigated.

\section{Experimental procedure}

\subsection{Materials and Devices}

Patterned ITO/glass with a sheet resistance of approximately $8 \Omega / \square$ was used as a substrate to prepare the PLEDs with a ITO/PEDOT:PSS/PVK/PFO-poss/LiF/Al structure. The substrates were cleaned ultrasonically with acetone, isopropyl alcohol (IPA) and deionized water. ${ }^{12)}$ The cleaned 
ITO substrates were then plasma-treated to improve the surface morphology and remove the organic particles, which led to good adhesion with the organic film layers. ${ }^{13-15)}$

The PEDOT:PSS [poly(3,4-ethylenedioxythiophene)-polystyrene sulfonate] and PFO-poss polymer materials were used as the hole injection layer (HIL) and emission layers (EML) of the PLED device. The PEDOT:PSS precursor solution was made by mixing with toluene and then filtered through a $0.45 \mu \mathrm{m}$ Milex filter. Then, the prepared solution was spin coated on the ITO/glass substrate at $1000 \mathrm{rpm}$ for 90 seconds. The coated PEDOT:PSS film was dried at $100{ }^{\circ} \mathrm{C}$ for $2 \mathrm{hrs}$ in a vacuum dry oven. For improving the light efficiency of the prepared PLED devices, the PVK [poly(N-vinylcarbazole)] as hole transport layer (HTL) was also dissolved with the mono-chlorobenzene and spin coated onto the PEDOT:PSS layer. After then, the PFOposs emitting materials were dissolved in a mixture of $1 \mathrm{wt} \%$ mono-chlorobenzene and toluene. Following this, the prepared PFO-poss solution was spin coated onto the PVK/PEDOT:PSS/ITO/glass substrate at successive rotation speeds of 1000 and $3000 \mathrm{rpm}$ for 20 seconds each, which was followed by annealing at 100 and $200{ }^{\circ} \mathrm{C}$ for 1,2 and 3 hours in order to investigate the low temperature annealing effect of the PFO-poss emitting film. These processes were carried out in a glove box under an $\mathrm{N}_{2}$ gas atmosphere to protect the devices from moisture and oxygen.

The LiF used as the electron injection layer (EIL) and aluminum cathode electrode ( $\mathrm{LiF} / \mathrm{Al})$ were deposited by the thermal evaporation method in a vacuum chamber with a base pressure of $5 \times 10^{-8}$ torr. An approximately $1 \mathrm{~nm}$ thick LiF layer as an EIL and $150 \mathrm{~nm}$ thick aluminum cathode electrodes $(\mathrm{LiF} / \mathrm{Al})$ were deposited by thermal evaporation.

Fig. 1 shows the energy band diagram and chemical structure of materials of the prepared PLED device.

\subsection{Measurements}

The surface morphology and roughness of the coated films were measured by Digital Instruments (Dimension 3100-IVA) atomic force microscopes (AFM). The atomic force microscopes quantitative surface analysis with resolution in the nanometer region in all three dimensions is possible. In this experiment, the silicon cantilevers integrated tip of $125 \mu \mathrm{m}$ length, and resonant frequency of $300 \mathrm{kHz}$ were used for tapping mode imaging. The crystal properties of the emission film layer were examined by X-ray diffraction (XRD). The electrical properties of the PLEDs were investigated using the HP4145B semiconductor measurement system. And for the measurement of optical properties, the luminance, spectrum wavelength and CIE (Commission Internationale de I'Eclairage) color chart were evaluated using CS-1000 sprectro-radiometer (Konica Minolta Co.).

\section{Result and Discussion}

\subsection{The annealing effect of PFO-poss emission film}

The patterned ITO/glass with the size of $1 \mathrm{X} 1 \mathrm{inch}$ square was used as starting substrates. A good surface morphology of ITO transparent electrode film might improve the interfacial adhesion between the ITO and organic film layer. Moreover, an improvement in the surface roughness of the ITO layer can allow the holes to be injected easily into the organic emission layer, which results in a low operation voltage of the device. Therefore, the sheet resistance of the ITO transparent electrode film needs to be reduced by optimizing the surface treatment of the electrode film. For this purpose, the electrical properties of ITO electrode films after the $\mathrm{O}_{2}$ plasma
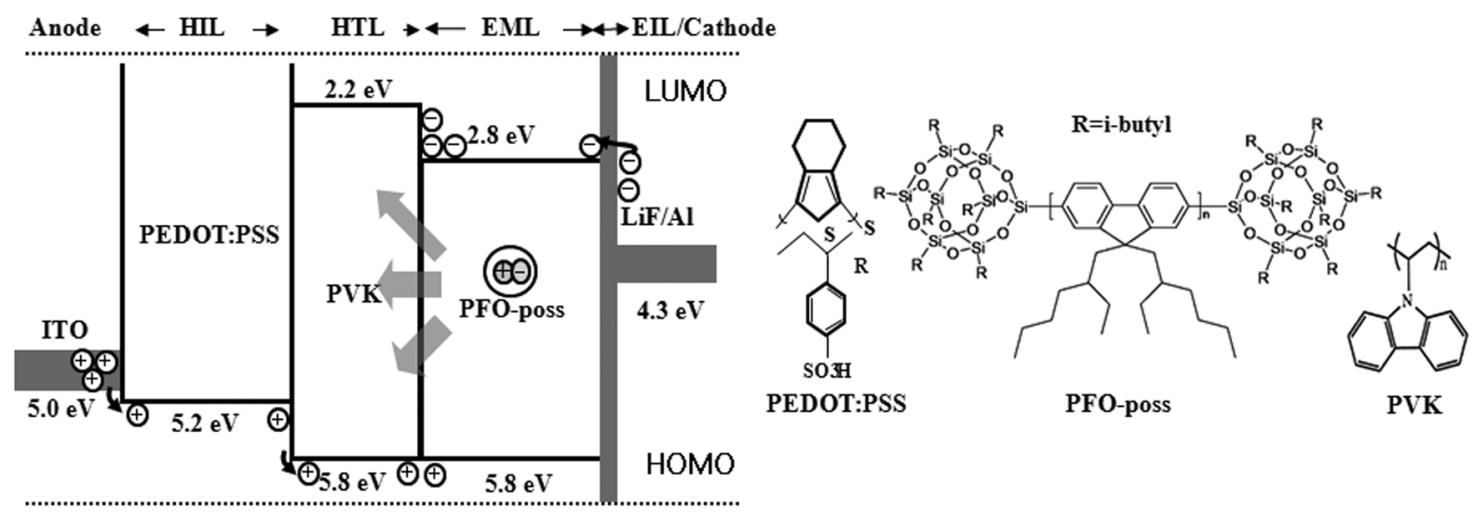

Fig. 1. Cross-sectional view of the PLEDs. 


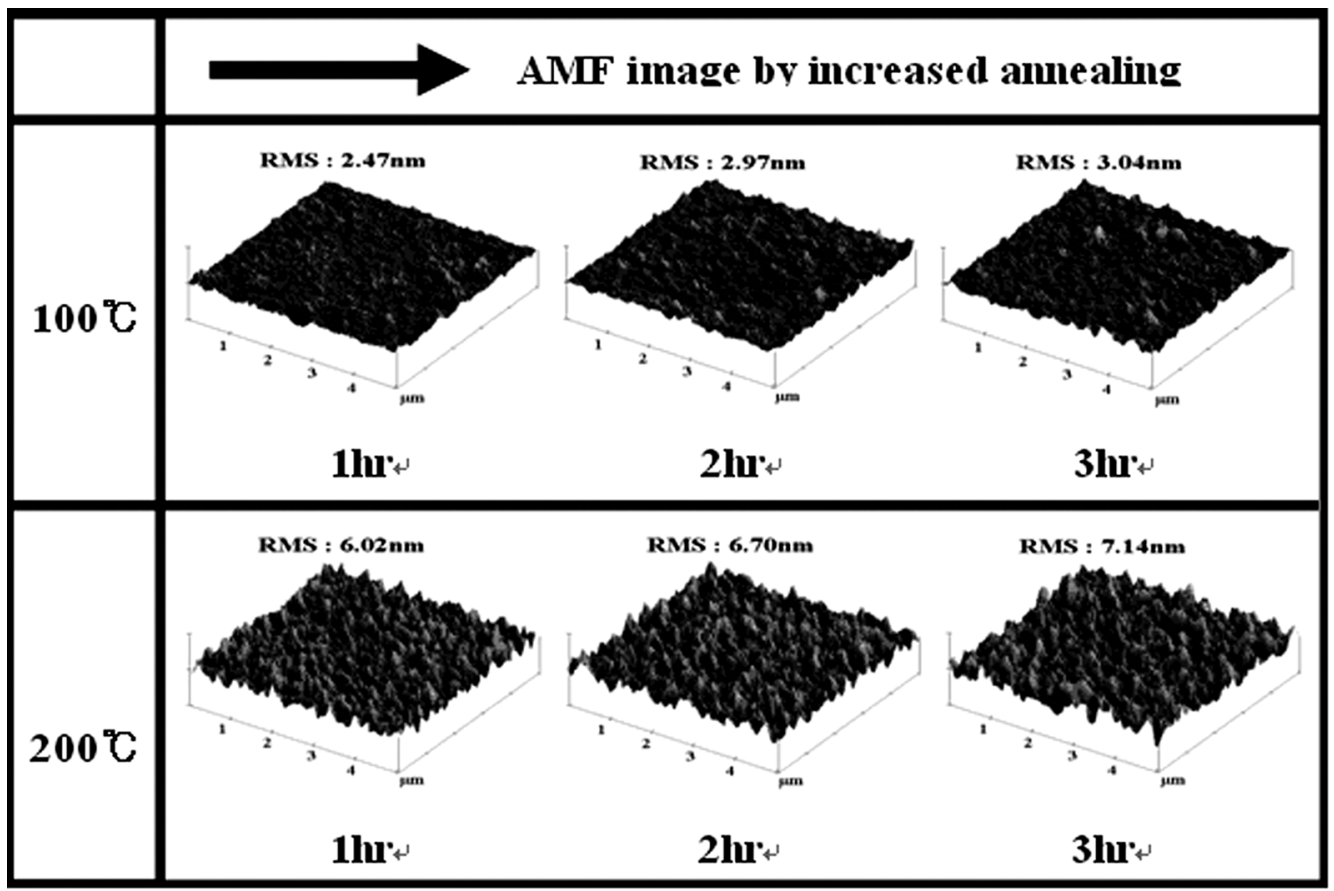

Fig. 2. AFM surface morphologies with the RMS values for the PFO-poss emission layer annealed at 100 and $200{ }^{\circ} \mathrm{C}$ for 1,2 and $3 \mathrm{hr}$.

treatment were examined by plasma treating the ITO/ glass substrates as functions of the $\mathrm{O}_{2}$ pressure, $\mathrm{RF}$ input power and treatment time as previous experiment. ${ }^{15)}$ In this experiment, the ITO/glass substrates, which were plasmatreated at $100 \mathrm{~W}$ in RF power for 30 seconds under $\mathrm{O}_{2}$ pressure of $40 \mathrm{mTorr}$, were used to manufacture the PLED device considering the optimum condition of the surface morphology and sheet resistance of the ITO film.

The annealing condition of PFO-poss emission layer of the PLED was optimized by the heat-treating of the prepared PLEDs at low temperatures and examining the electrical and optical properties. The emission PFO-poss organic films were annealed at 100 and $200{ }^{\circ} \mathrm{C}$ for 1,2 and 3 hours.

Fig. 2 shows the surface morphologies and RMS values of the PFO-poss emission film layers under various annealing conditions. The RMS value increased slightly with increasing annealing time from 1 to 3 hours. On the other hand, the RMS values increased drastically with increasing annealing temperature from 100 to $200{ }^{\circ} \mathrm{C}$, indicating a rough film surface at a higher temperature. The RMS values for the PFO-poss emission film with heat treatment at $100^{\circ} \mathrm{C}$ was increased from 2.47 to $3.04 \mathrm{~nm}$, and also at $200{ }^{\circ} \mathrm{C}$ increased from 6.02 to $7.14 \mathrm{~nm}$ with increasing annealing time from 1 to 3 hours. This result may be caused to the crystallization of the PFO-poss film annealed at $200{ }^{\circ} \mathrm{C}$.

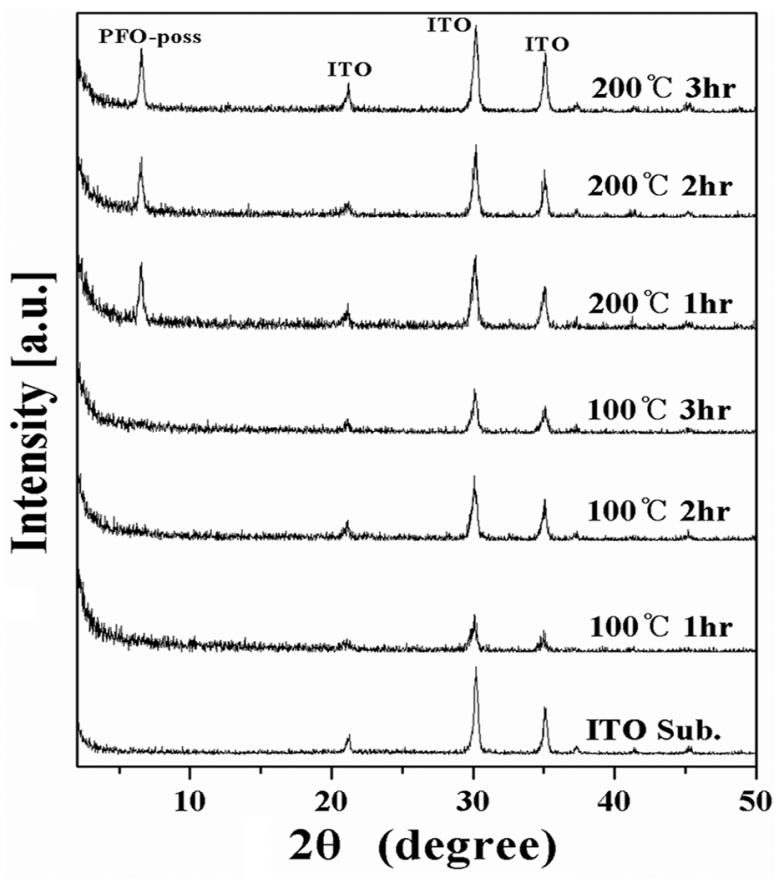

Fig. 3. XRD patterns of the PFO-poss films annealed at 100 and $200{ }^{\circ} \mathrm{C}$ for 1,2 and $3 \mathrm{hr}$.

Fig. 3 shows the XRD patterns of the PFO-poss emission layer under various annealing conditions. The PFO-poss crystalline peaks appeared at $2 \theta$ (theta) $=6.5^{\circ}$ for the sample annealed at $200{ }^{\circ} \mathrm{C}$. However, there was no diffraction 


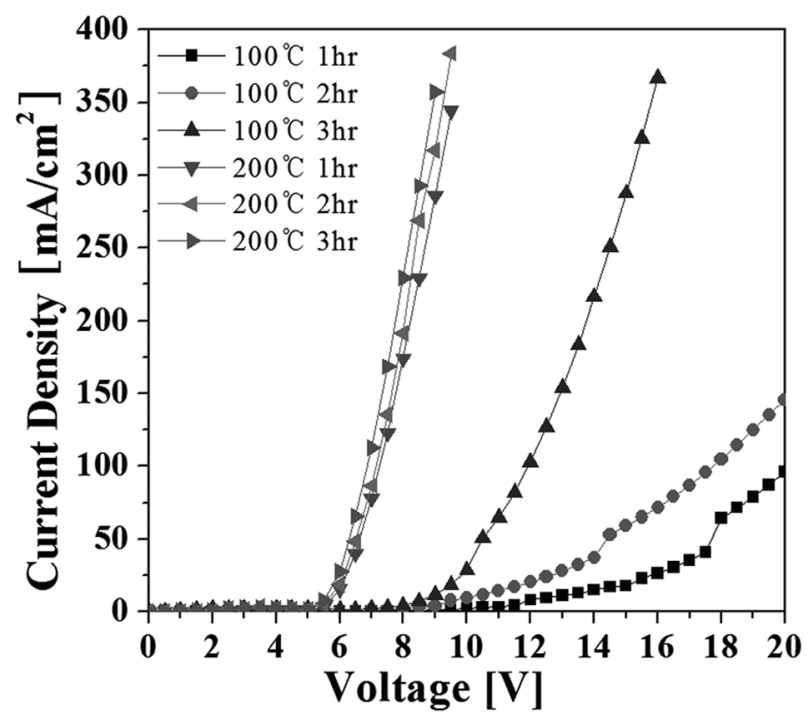

Fig. 4. The current density versus the voltage characteristics of the PLEDs with a PFO-poss emission layer annealed at 100 and $200{ }^{\circ} \mathrm{C}$ for 1,2 and $3 \mathrm{hr}$.

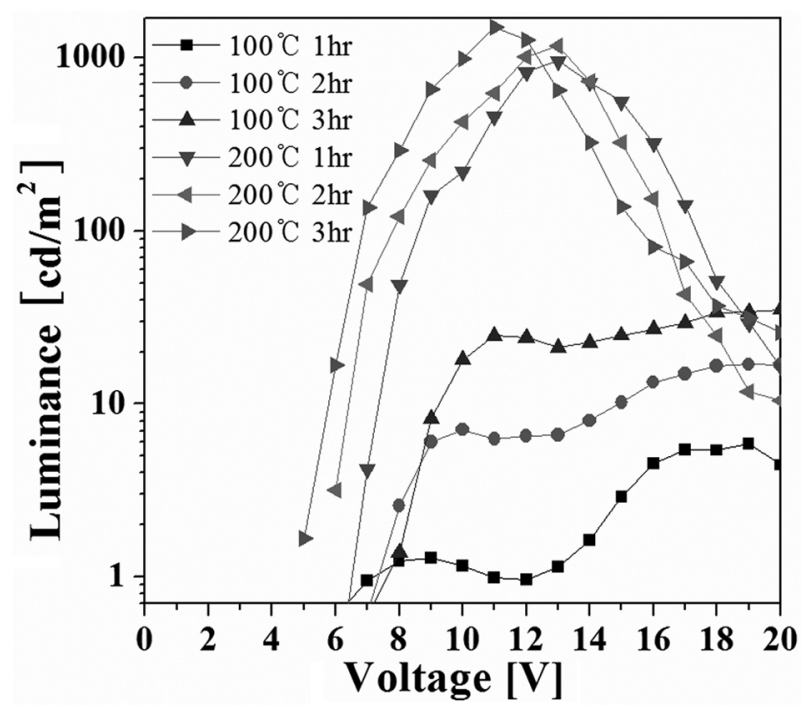

Fig. 5. The luminance versus voltage characteristics of the PLEDs with a PFO-poss emission layer annealed at 100 and $200{ }^{\circ} \mathrm{C}$ for 1,2 and $3 \mathrm{hr}$.

peak for the PFO-poss film layer annealed at $100{ }^{\circ} \mathrm{C}$ regardless of the annealing time, indicating the PFO-poss film layer is amorphous phase. In contrast, the XRD measurements show that the PFO-poss emission layer can be crystallized partially when the samples are annealed at $200{ }^{\circ} \mathrm{C}$ for 1 to 3 hours. The crystallized phase of the emission layer can lead to an improvement of the luminance properties of PLED devices by means of the increased carrier mobility and excitons (electron and hole pairs) recombination. $^{16)}$

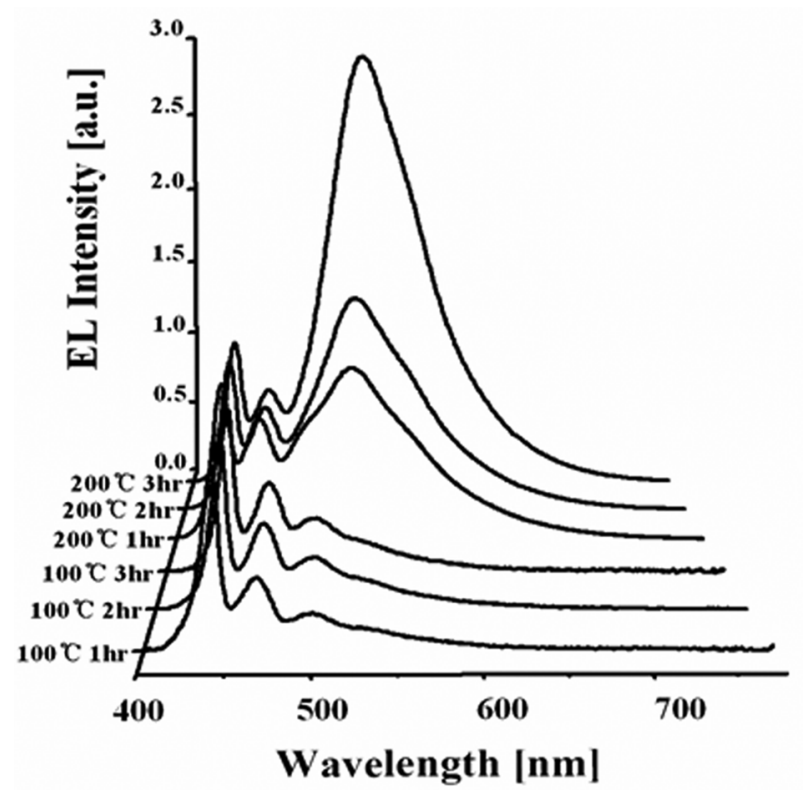

Fig. 6. The emission spectra of the PLEDs with a PFO-poss film annealed at 100 and $200{ }^{\circ} \mathrm{C}$ for 1,2 and $3 \mathrm{hr}$.

\subsection{Electrical and Optical Properties of the} prepared PLED devices

The effect of annealing the PFO-poss emission layer was examined by measuring the electrical and optical properties of the PLEDs.

Fig. 4 shows the current density versus voltage characteristics for the PLEDs with the PFO-poss emission layer annealed at 100 and $200{ }^{\circ} \mathrm{C}$ for 1,2 and 3 hours. The current density of the PLED device annealed at $100{ }^{\circ} \mathrm{C}$ increased significantly with increasing annealing time from 1 to 3 hours. On the other hand, the current density of the PLED with PFO-poss film annealed at $200{ }^{\circ} \mathrm{C}$ showed much larger values than those annealed at $100{ }^{\circ} \mathrm{C}$. The turn-on voltage decreased from approximately 8 to $5 \mathrm{~V}$ with increasing annealing temperature from 100 to $200{ }^{\circ} \mathrm{C}$.

Fig. 5 shows the change in luminance as a function of input voltage for PLEDs with a PFO-poss film annealed at 100 and $200{ }^{\circ} \mathrm{C}$ for 1,2 and 3 hours. The luminance of PLED devices with the PFO-poss film annealed at $100{ }^{\circ} \mathrm{C}$ increased from about 6 to $36 \mathrm{~cd} / \mathrm{m}^{2}$ with increasing annealing time from 1 to 3 hours. The maximum luminance of $1497 \mathrm{~cd} / \mathrm{m}^{2}$ was observed in the PLED device with the PFO-poss film annealed at $200{ }^{\circ} \mathrm{C}$ for 3 hours. The results of the electrical and optical properties of PLEDs at various annealing conditions suggest that the higher current density and luminance are related to the increased carrier injection into the emission layer ${ }^{17)}$ through the crystallization of the 


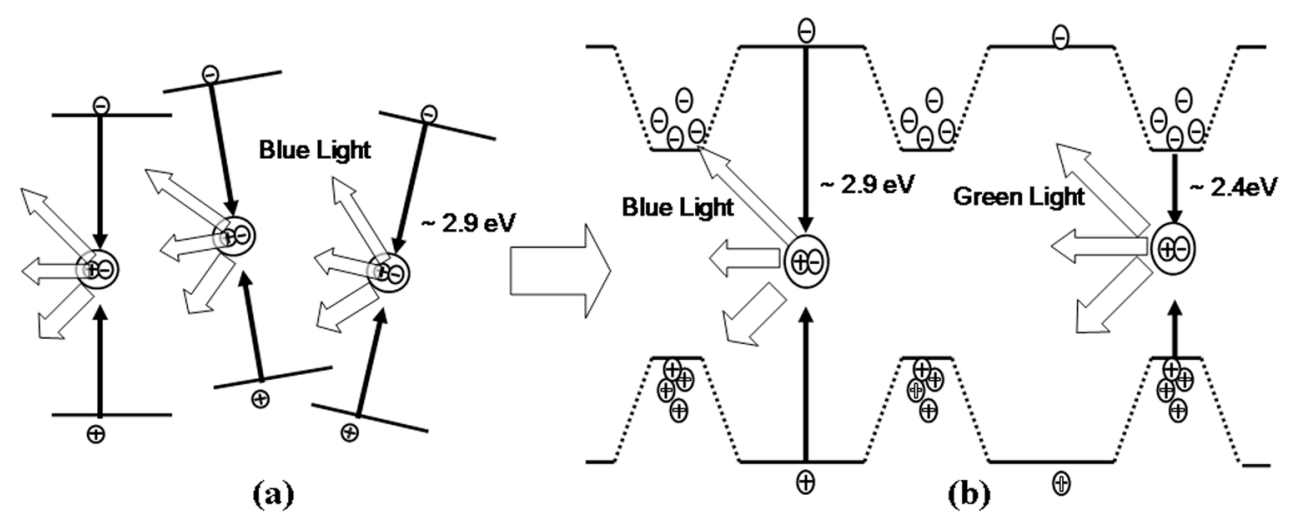

Fig. 7. The schematic optical energy band diagrams of the PFO-poss films annealed at the (a) $100{ }^{\circ} \mathrm{C}$ and (b) $200{ }^{\circ} \mathrm{C}$.

Table 1. The summarized electrical and optical properties of PLEDs according to PFO-poss emission layer at the annealing conditions.

\begin{tabular}{lccccc}
\hline $\begin{array}{c}\text { Annealing } \\
\text { Conditions of } \\
\text { PFO-poss film }\end{array}$ & RMS Value (nm) & $\begin{array}{c}\text { Crystallization } \\
(2 \text { theta) }\end{array}$ & $\begin{array}{c}\text { Current Density } \\
\left(\mathrm{mA} / \mathrm{m}^{2} \text { at } \mathrm{V}\right)\end{array}$ & $\begin{array}{c}\text { Max. Luminance } \\
\left(\mathrm{cd} / \mathrm{m}^{2} \text { at V) }\right.\end{array}$ & $\begin{array}{c}\text { Turn-on } \\
\text { Voltage }(\mathrm{V})\end{array}$ \\
\hline 1 hour at $100^{\circ} \mathrm{C}$ & 2.47 & Amorphous & 18 at $14 \mathrm{~V}$ & 6 at $19 \mathrm{~V}$ & 7 \\
2 hours at $100^{\circ} \mathrm{C}$ & 2.97 & Amorphous & 65 at $14 \mathrm{~V}$ & 10 at $18 \mathrm{~V}$ & 8 \\
3 hours at $100^{\circ} \mathrm{C}$ & 3.04 & Amorphous & 221 at $14 \mathrm{~V}$ & 36 at $17 \mathrm{~V}$ & 8 \\
1 hour at $200^{\circ} \mathrm{C}$ & 6.02 & Crystallized $\left(6.5^{\circ}\right)$ & 227 at $8 \mathrm{~V}$ & 856 at $13 \mathrm{~V}$ & 7 \\
2 hours at $200^{\circ} \mathrm{C}$ & 6.70 & Crystallized $\left(6.5^{\circ}\right)$ & 270 at $8 \mathrm{~V}$ & 1086 at $12 \mathrm{~V}$ & 6 \\
3 hours at $200^{\circ} \mathrm{C}$ & 7.14 & Crystallized $\left(6.5^{\circ}\right)$ & 288 at $8 \mathrm{~V}$ & 1497 at $11 \mathrm{~V}$ & 5 \\
\hline
\end{tabular}

PFO-poss film annealed at $200^{\circ} \mathrm{C}$, as shown in Fig. 3.

Fig. 6 shows the emission spectra of the PLEDs with the PFO-poss film layer annealed at 100 and $200{ }^{\circ} \mathrm{C}$ for 1 , 2 and 3 hours. The emission intensities of the $3^{\text {rd }}$ peaks (wavelength approx. $525 \mathrm{~nm}$ ) for the PLEDs with the PFOposs film annealed at $200{ }^{\circ} \mathrm{C}$ was higher than $1^{\text {st }}$ emission peak (wavelength approx. $435 \mathrm{~nm}$ ) annealed at $100{ }^{\circ} \mathrm{C}$. The major emission peaks along with the transition responsible for the change of the energy band gap due to interaction between the excited state of the molecule and ground state of other molecule of PFO-poss. ${ }^{18)}$

The emission spectra also increased significantly with increasing annealing time from 1 to 3 hours. This suggests that the light emission color shifted to a longer wavelength from blue to green. From the emission spectra measurement, it was estimated that electron/hole pairs are formed at a lower energy level when the PFO-poss films are annealed at $200{ }^{\circ} \mathrm{C}$. Y. Shi reported ${ }^{19)}$ that the emission color of the PLED shifted to a longer wavelength with increasing annealing time.

We conjecture that the shift to longer wavelength (color shift) is related to the change of energy band gap between two samples with PFO-poss annealed at 100 and $200{ }^{\circ} \mathrm{C}$.

Fig. 7 shows the schematic optical energy band diagrams of the PFO-poss film annealed at the (a) $100{ }^{\circ} \mathrm{C}$ and (b) $200{ }^{\circ} \mathrm{C}$. As shown in energy band diagram, the optical band gap energy between highest occupied molecule orbit (HOMO) and lowest unoccupied molecule orbit (LUMO) can be changed with smaller value up to about $2.4 \mathrm{eV}$ when the PFO-poss film layer is crystallized at $200{ }^{\circ} \mathrm{C}$. Whereas, the energy band gap was estimated about $2.9 \mathrm{eV}$ of the PFO-poss film annealed at $100{ }^{\circ} \mathrm{C}$. These energy band gaps were calculated by the equation (1).

$$
E=h v=\frac{h \times c}{\lambda}
$$

Where, E is the energy band gap between HOMO and LUMO level, $h$ is Planck's constant $\left(6.623 \times 10^{-34} \mathrm{~J} \cdot \mathrm{s}\right), c$ is the speed of light $\left(3 \times 10^{8} \mathrm{~m} / \mathrm{s}\right)$ and $\lambda$ is the main emission peaks of PLEDs (435 and $525 \mathrm{~nm}$ in wavelength).

The electrical properties of PLEDs according to PFOposs emission layer at the annealing conditions were summarized in Table 1.

\section{Conclusions}

PLED devices with ITO/PEDOT:PSS/PVK/PFO-poss/ $\mathrm{LiF} / \mathrm{Al}$ structure were prepared on the plasma-treated ITO/ 
glass substrates. The dependences of the electrical and optical properties of the PLED devices on the annealing conditions of PFO-poss emission layer were examined. AFM images showed that the RMS values of the PFOposs emission film with heat treatment at $100{ }^{\circ} \mathrm{C}$ for $1 \mathrm{hr}$ was $2.47 \mathrm{~nm}$ and increased to $6.02 \mathrm{~nm}$ when the PFO-poss film was annealed at $200{ }^{\circ} \mathrm{C}$ for $1 \mathrm{hr}$. This result may be caused by the crystallization of PFO-poss emission film from the XRD patterns. The luminance of the PLEDs increased from 36 to $1497 \mathrm{~cd} / \mathrm{m}^{2}$ at $11 \mathrm{~V}$ as the annealing temperature of the PFO-poss film increased from 100 to $200{ }^{\circ} \mathrm{C}$. The current density increased and the turn-on voltage decreased with increasing the annealing temperature. With increasing annealing temperature and time of the PFO-poss emission films, strong emission peaks were observed at approximately $525 \mathrm{~nm}$, suggesting an emission color shift from blue to green. It seems that the shift to longer wavelength (color shift) is related to the change of energy band gab between two samples with PFO-poss film annealed at 100 and $200{ }^{\circ} \mathrm{C}$.

\section{Acknowledgement}

The present research was conducted by the research fund of Dankook University in 2008

\section{References}

1. C. W. Tang, S. A. Vanslyke, Appl. Phys. Lett., 51, 913 (1987).
2. J. G. Jang, S. J. Shin, E. J. Kang, H. W. Kim, H. J. Chang, M. W. Oh, Y. S. Kim, J. Y. Lee, M. S. Gong and Y. K. Lee, Kor. J. Mater. Res., 16(4), 253 (2006).

3. B. W. D'Andrade, R. J. Holmes and S. R. Forrest, Adv. Mat. 16, 624 (2004).

4. M. Mazzeo, D. Pisignano, F. Della Sala, J. Thompson, R. I. Blyth, G. Gigli, G. Sotgiu and G. Barbareiia, Appl. Phys. Lett., 82, 334 (2003).

5. H. Zhang, Y. Li, M. Xie, Q. Jiang, J. Peng and Y. Cao, J. Mater. Sci., 42, 4476 (2007).

6. T. H. Kim, J. H. Park, T. W. Lee and O. O. Park, Polymer, 45, 8567 (2004).

7. T. W. Lee, O. O. Park, Appl. Phys. Lett., 77, 3334 (2000).

8. S. W. Ko, B. J. Jung, N. S. Cho and H. K. Shim, Kor. Chem. Soc., 23(9), 1235 (2003).

9. M. Bender, W. Seeling, C. Dabe, H. Frankenberger, G. Ocker and J. Stollenwerk, Thin Solid Films., 326, 72 (1998).

10. Y. Xu, J. Peng, Y. Mo, Q. Hou and Y. Cao, Appl. Phys. Lett., 86, 163502 (2006).

11. Y. Xu, J. Peng, J. Jiang, W. Wu, W. Yang and Y. Cao, Appl. Phys. Lett., 87, 193502 (2005).

12. R. C. Jaeger, Modular Series Vol V, $2^{\text {nd }}$ Edition, Prentice Hall Inc, 21 (2002).

13. J. Y. Park, H. S. Kim, D. H. Lee, K. H. Kwon and G. Y. Yeom, Surface and Coating Tech., 131, 247 (2000).

14. I. M. Chan, F. C. N. Hong, Thin Solid Film, 444, 254 (2003).

15. S. B. Shin, S. C. Gong, J. K. Jang, M. S. Gong, Y. C. Chang, Y. B. Sun and H. J. Chang, J. Appl. Polym. Sci., 110, 3678 (2008).

16. G. Lussem, J. H. Wendorff, Polym. Adv. Tech., 9, 443 (1998).

17. W. Zhao, T. Cao and J. M. White, Adv. Funct. Mat., 14, 783 (2004).

18. D. Gupta, K. M. Deepak, Optical Materials, 28, 295 (2006).

19. Y. Shi, J. Liu and Y. Yang, J. Appl. Phys., 87, 4254 (2000). 